Research Article

\title{
Assessment of Potential Property of Baobab Fruit Pulp Derived Pectin as a Pharmaceutical Excipient
}

\author{
V.T.Iswariya ${ }^{1 *}$, Annamma Devi.G.S ${ }^{1}$ \\ 1. Department of Pharmaceutics, GITAM institute of pharmacy, GITAM university ( Deemed to be University), Vishakhapatnam, Andhra \\ Pradesh, India. \\ *Corresponding author's E-mail: nivasbiotech1979@gmail.com
}

Received: 02-01-2021; Revised: 18-02-2021; Accepted: 26-02-2021; Published on: 20-03-2021.

\section{ABSTRACT}

The main goal about of the current study is extraction of baobab fruit peel pulp containing pectin as a potential excipient and additional characterization for its beneficial constructive choice as a alternative potent pharmaceutical excipient. The pectin used to be subjected to phytochemical screening to conformity with phytochemical then and physicochemical characterization about its safety measures and appropriateness/suitability in conformity with to be use as a disintegrating agent. FTIR-spectroscopic analysis, DSC-thermal analysis and XRD research studies were performed with subject as baobab fruit pectin powder. Piroxicam was selected as a model drug, direct compression technique was utilised as for preparation of piroxicam tablets by followed with distinct concentrations of pectin powder derived from baobab fruit and synthetic binding agent $\mathrm{PVPk}_{30}$ as a concentration of $5 \% \mathrm{w} / \mathrm{w}$. The granules prepared are be subjected to assess pre compression parameters and granules are be lubricated with talc along with magnesium stearate and fallowed by compression result into the tablets. Pharmaceutical properties of pectin powder such as Haunser ratio, carr's compressible index and critical angle of repose studies were assessed and results were determined satisfactory. In-vitro dissolution study shows that release rate dimension of drug is decreased with increase in the baobab fruit peel pectin powder percentage in the formulation. Based on the above findings concluding baobab fruit peel pectin powder has showed good binding property and the study strongly suggesting that baobab fruit peel pulp containing pectin as a potential pharmaceutical excipient.

Keywords: Baobab fruit peel pectin powder, Piroxicam, FTIR, XRD and DSC.

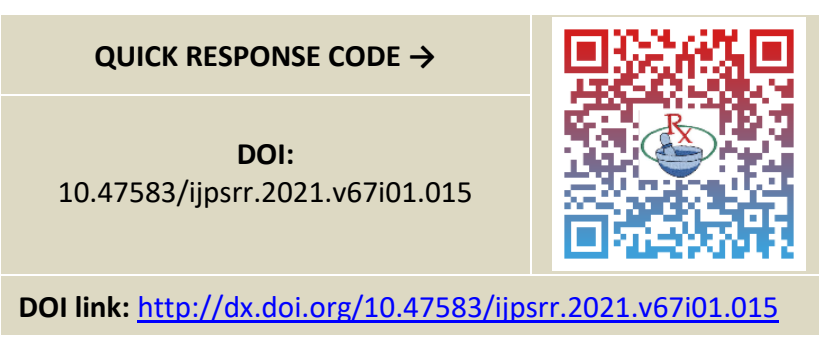

\section{INTRODUCTION}

F or quite a long time man has instituted high quality use about materials from natural origin in the characteristic cause in the therapeutics/medicinal at pharmaceutical field. Common natural origin materials hold advantages upon synthetic substances because they have points of interest over manufactured materials since they are nontoxic and non-harmful, more affordable, freely accessible, biodegradable yet safe to consumable sources ${ }^{1}$. They are utilized as a thickening, much binding, suspending, emulsifying, stabilizing agents in pharmaceutical industries and utilized as matrices frameworks for sustained release of medications ${ }^{2,3}$.

The globally most of terrestrial plants contained a multifunctional constituent like pectin within cell mass of plants. Pectin is a structural acidic non starch hetro-poly carbohydrate and it consists of major component of Dgalacturonic acid with sugar acid derived from galactose ${ }^{4}$. The pectins carboxyl group of D- galacturonic acid might be esterified with methanol/acetic acid, during pectin extraction this proportion may diminished to varying degrees. The percentage of esterified groups of the pectins are expressed as on basis of degree of methylation low methoxy pectins (LM-Pectins) and high methoxy pectins(HM-Pectins) respectively. The less than 50\% esterfied pectins (LM-Pectins) forms gels like thermo reversible by interaction with bivalent $\mathrm{Ca}^{2+}$ ions particularly at pH 3.0-4.5. In case of greater than 50\% esterfied pectins (HM-Pectins) rapidly forms gels like thermo irreversible under acidic circumstances in the attendance of high concentration of sugar at low $\mathrm{pH}$ than 3.5. Pectins are most predominantly utilizing as gelling agent and additionally it also acts as thickener. In discriminate of upon hearty aspects, pectin actually remains a promising pharmaceutical excipient for oral drug delivery. In the present study, we have extracted pectin from baobab fruit pulp and verified its potentials for using as disintegrating agent in the piroxicam.

\section{MATERIALS AND METHODS}

Piroxicam is acquired from Wockhardt pharmaceutical pvt. Ltd, Mumbai, India and pectin powder was extracted from baobab fruit pulp in the laboratry. D-Mannitol $\left[\mathrm{C}_{6} \mathrm{H}_{14} \mathrm{O}_{6}\right]$, Pvpk30, Talc $\left[\mathrm{Mg}_{3} \mathrm{Si}_{4} \mathrm{O}_{10}(\mathrm{OH})_{2}\right]$, Magnesium stearate $\left[\mathrm{Mg}\left(\mathrm{C}_{18} \mathrm{H}_{35} \mathrm{O}_{2}\right)_{2}\right]$ and Lactose are of analytical grade.

\section{Extraction of Baobab Fruit Pulp Pectin Powder}

The ripped baobab fruits were acquired from local tree. The collected fruits were painstakingly washed and shade dried for 24 hrs fallowed by further drying carried in a hot 
air oven at $60^{\circ} \mathrm{C}$ result in dried fruit pulp. Dried fruit pulp material was slice into small pieces and made into powdered by using home electric greater. Fruit pulp powdered was further subjected to passed through a sieve no 20 .The peel powder of $200 \mathrm{gms}$ was once dissolved in $1000 \mathrm{ml}$ of distilled water and additionally added $1 \mathrm{gm}$ of citric acid to keep up acidic $\mathrm{pH}$. To extract pectin, whole prepared solution was exposed to reflux condensation for $6 \mathrm{hrs}$ at $70^{\circ} \mathrm{C}$. The extracted as part of an extraction unit was a whatman cellulose thimble with $80 \mathrm{~mm}$ external length and $33 \mathrm{~mm}$ internal. Warm acid extract was taken in a cheese cloth sack to squeezed result concentrated juice and cool it up to $4^{\circ} \mathrm{C}$. Pectin was once precipitated through ethanol $(2 \mathrm{v} / \mathrm{v})$ : water $(1 \mathrm{v} / \mathrm{v})$ treatment followed via non-stop through stirring for 15 min then permitted to kept stand for $2 \mathrm{hrs}$. Coagulated Pectin was separated through cheese fabric, washes with alcohol (95\%) and squeezed. Pressed pectin was additionally dried to consistent load at 35 to 45 ㅇ․ Hard cake of pectin was ground and passed through a sieve No.60, store with in a desiccators for further utilization ${ }^{6}$.

\section{Preliminary phytochemical screening of baobab fruit pulp pectin}

The baobab fruit pulp pectin powder was subjected to the phytochemical analysis to determine presence of phyto constituents like tannins, carbohydrates, alkaloids, glycosides, amino acids and proteins by using standard methods ${ }^{7}$ as shown in Table no1.

\section{Physicochemical characterization of baobab fruit pulp pectin powder}

The physicochemical characterization of baobab fruit pulp pectin powdered assed by soluble in water than in other solvents, percentage loss on drying, $\mathrm{pH}$ and ash value etc were determined as results are shown in Table no 2.

Table 1: Phyto chemical characterization of Baobab fruit pulp pectin powder

\begin{tabular}{|c|c|c|c|c|}
\hline S.no & \multicolumn{2}{|c|}{ Name of the test carried out } & Test result & Inference \\
\hline \multirow{3}{*}{1} & \multirow{3}{*}{ Test for alkaloids } & Mayer's test & - & Absent \\
\hline & & Wagner test & - & Absent \\
\hline & & Hager's test & - & Absent \\
\hline \multirow{3}{*}{2} & \multirow{3}{*}{$\begin{array}{c}\text { Test for } \\
\text { carbohydrates }\end{array}$} & Molish test & + & Present \\
\hline & & Fehling's test & + & Present \\
\hline & & Benedict's test & + & Present \\
\hline \multirow{2}{*}{3} & \multirow{2}{*}{ Test for glycosides } & Liebermann- Burchard's test & - & Absent \\
\hline & & Legal's test & - & Absent \\
\hline \multirow{3}{*}{4} & \multirow{3}{*}{ Test for tannins } & Lead acetate test & - & Absent \\
\hline & & Ferric chloride test & - & Absent \\
\hline & & Aqueous bromine test & - & Absent \\
\hline 5 & Mucilage test & Ruthenium red test & - & Absent \\
\hline \multirow{3}{*}{6} & \multirow{3}{*}{$\begin{array}{l}\text { Test for amino } \\
\text { acids and proteins }\end{array}$} & Ninhydrin test & - & Absent \\
\hline & & Millons test & - & Absent \\
\hline & & Biuret test & - & Absent \\
\hline
\end{tabular}

Table 2: Physicochemical characterization of Baobab fruit pulp pectin powder

\begin{tabular}{|c|c|c|c|c|c|}
\hline Parameter & Color & Odour & Nature & Solubility \\
\hline Results & Brown colour & Characteristic & Amorphous & Soluble in water & $\begin{array}{c}\text { Insoluble in acetone, methanol, ether and } \\
\text { ethanol. }\end{array}$ \\
\hline
\end{tabular}

\section{FT-IR Studies}

Pure drug piroxicam, baobab fruit pulp pectin powdered, prepared formulations are being studied for FTIR spectra ${ }^{8}$ are shown in Fig no 1 and 2.

\section{Scanning Electron Microscopy}

SEM studies are performed to understanding surface morphological characters of the extracted pectin powder of baobab fruit pulp as shown in Fig no 4.

\section{Thermal analysis [DSC studies]}

The DSC analytical studies are performed to know any chemical interactions in between of pure piroxicam, pectin powder of baobab fruit pulp and prepared tablet formulations.

\section{Formulation of Piroxicam tablets}

Piroxicam was used as model drug; direct compression method was used for preparation of the piroxicam tablets. 
Drug and excipients are passed through the sieve no.60 individually. Piroxicam, baobab fruit pulp pectin powder, mannitol and lactose were added and mixed uniformly. The procedure was followed with different concentrations of baobab fruit pulp pectin powder and $5 \% \mathrm{w} / \mathrm{w}$ concentration of PVPk30 as synthetic binding agent. The prepared granules were subjected to evaluate pre compression parameters. Granules were lubricated with magnesium stearate, talc and were compressed into the tablets of $200 \mathrm{mg}$, using 10 station rotary tablet compression machines ${ }^{9}$ as showed in table no.3.

Table 3: Formulation of Piroxicam tablets using different amounts of Baobab fruit pulp pectin powder

\begin{tabular}{|c|c|c|c|c|c|c|c|c|c|}
\hline Materials & F-1 & F-2 & F-3 & F-4 & F-5 & F-6 & F-7 & F-8 & F-9 \\
\hline Drug:piroxicam & $20 \mathrm{mg}$ & $20 \mathrm{mg}$ & $20 \mathrm{mg}$ & $20 \mathrm{mg}$ & $20 \mathrm{mg}$ & $20 \mathrm{mg}$ & $20 \mathrm{mg}$ & $20 \mathrm{mg}$ & $20 \mathrm{mg}$ \\
\hline Pvpk30 & 10 & 10 & 10 & 10 & 10 & 10 & 10 & 10 & 10 \\
\hline $\mathbf{X p}$ & 2.50 & 3.75 & 5.0 & 7.25 & 8.50 & 9.75 & 11 & 12.25 & 13.5 \\
\hline Mannitol & 133.5 & 132.25 & 131 & 128.75 & 127.5 & 126.25 & 125 & 123.75 & 122.5 \\
\hline Lactose & 30 & 30 & 30 & 30 & 30 & 30 & 30 & 30 & 30 \\
\hline Mg Ste & 2 & 2 & 2 & 2 & 2 & 2 & 2 & 2 & 2 \\
\hline Talc & 2 & 2 & 2 & 2 & 2 & 2 & 2 & 2 & 2 \\
\hline Total & 200 & 200 & 200 & 200 & 200 & 200 & 200 & 200 & 200 \\
\hline
\end{tabular}

\section{Assessment of pre-formulation studies of Piroxicam Granules}

\section{Angle of repose}

It was assessed by using fixed funnel method and it was calculated with the formula of, Angle of Response[ $\theta]=\tan ^{-}$ ${ }^{1}$ [height of pile $(H) /$ radius of the base of pile $\left.(R)\right]$

\section{Compressibility Index}

The compressibility index was fast and simple method to know powder flow characteristics. The compressibility index was determined by measuring both the Tapped bulk density and untapped bulk density of a powder, it was calculated by using formula:

$$
\text { Percent compressibility Index }=\frac{\text { Tapped bulk density }- \text { Un Tapped bulk density }}{\text { Tapped bulk density }} \text { X100 }
$$

\section{Assessment of prepared Tablets}

\section{Weight Variation Test}

Twenty randomly chosen tablets were individually weighed and collectively in a single panoramic balance. The percentage deviation and weight average was noted was calculated.

\section{Thickness and Hardness Test}

Six tablets were taken in use at random and tablet hardness was calculated by using of Monsanto hardness tester. The hardness was expressed in $\mathrm{kg} / \mathrm{cm}^{2}$. The diameter and thickness also measured by using of vernier caliper.

\section{Friability Test}

From each batch twenty tablets were selected randomly and tested at a time. Collective weight of tablets were determined prior to test (W1g) and after to the test (W2g). The percentage was calculated by the formula:

$$
\text { Percentage Friability }=\frac{\mathrm{W} 1-\mathrm{W} 2}{\mathrm{~W} 1} \mathrm{X} 100
$$

\section{Drug content}

Individually 5 tablets were weighed and collectively powdered. The average powder equivalent of the tablets weight was weighed and the drug was extracted in a pH 6.8 phosphate buffer, there after spectro-photometrically drug content was determined. After with a suitable dilution absorbance was measured at $334 \mathrm{~nm}$ by using UV spectrophotometer.

\section{Test for Disintegration}

According to I.P. method disintegration test was performed. Chosen 6 tablets were individually positioned in glass tubes of the disintegration device. The temperature of disintegration fluid was maintained at $37^{\circ} \mathrm{C}$ and the time duration required for disintegration was observed and noted.

\section{In-vitro dissolution studies}

The dissolution studies of the prepared piroxicam tablets were performed by using a $\mathrm{pH} 6.8$ phosphate buffer at $37^{\circ} \mathrm{C}$ and in case of tablets, paddle rotation speed was maintained at $50 \mathrm{rpm}$. Samples were collected in a equal intervals of every five minutes up-to 1hour and also maintained a constant volume $(900 \mathrm{ml})$ of the dissolution support medium up-to $1 \mathrm{hr}$ by replacing fresh medium at each time intervals. All Samples were spectroscopically analyzed at $334 \mathrm{~nm}$ by using UV Spectrophotometer. 


\section{Stability Studies}

According to the ICH guide-lines stability studies were performed on optimized formulation by storing tablets at $40^{\circ} \mathrm{C} / 75 \% \mathrm{RH}$ for 90 days.

\section{RESULTS AND DISCUSSION}

Phytochemical characterization of baobab fruit pulp pectin powder results revealed that baobab fruit pulp pectin powder showed positive result with molish test, Fehling's test and Barford test. This demonstrates presence of carbs and diminishing sugar in the baobab fruit pulp pectin powder. The negative outcomes were observed in case of test for tannins, alkaloids, proteins, glycosides and amino acids the results are shown in table no.1.
According to the physic-chemical properties of baobab fruit pulp pectin powder is dissolvable in $\mathrm{H}_{2} \mathrm{O}$ and insoluble in $\left(\mathrm{CH}_{3}\right)_{2} \mathrm{CO}$, indicates that's it should not soluble in other organic solvents also. $\mathrm{pH}$ of baobab fruit pulp pectin powder solution showed. Microbial studies reveal that there is no microbial growth after three days study

FT-IR spectra for pure piroxicam (in the Figure 1), baobab fruit pulp pectin powder and optimized piroxicam tablet formulation (in the Figure 2) are shown. The characteristic absorption peak of pure piroxicam was retained in the spectra of a tablet formulation. It was noticed that no marked changes in the absorption peaks of model drug in the final formulation. Therefore, there is no drug interaction with pectin powder of baobab fruit pulp and also with other excipients utilized in the study.

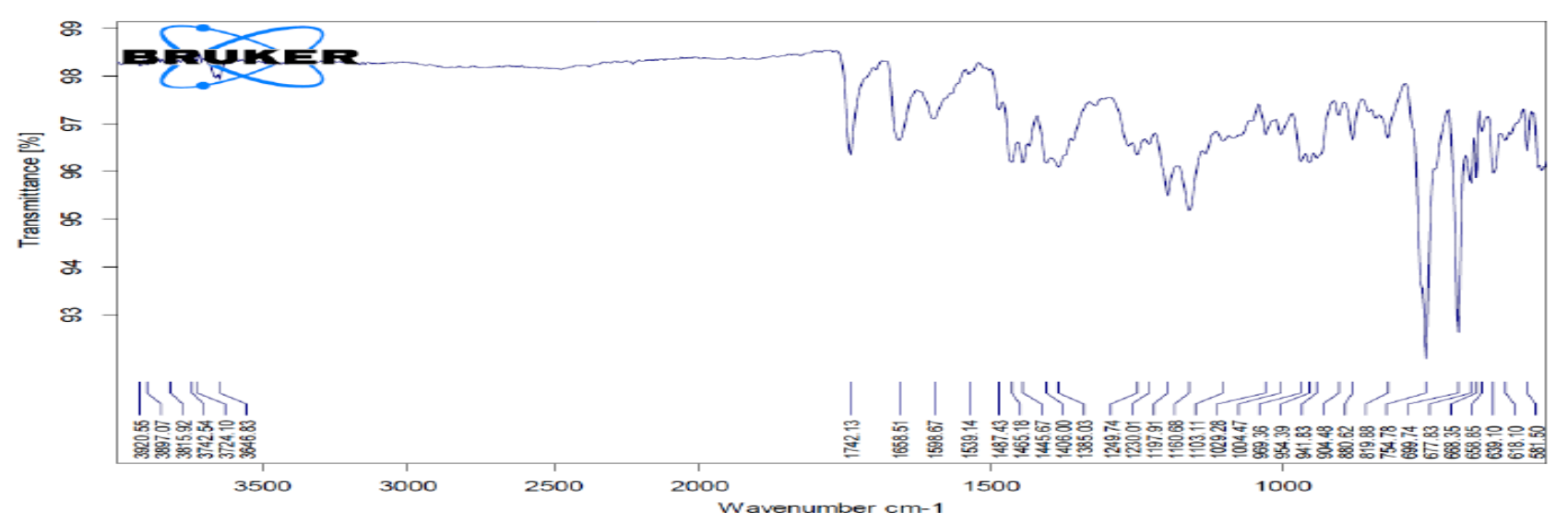

Figure 1: FT-IR spectra of Piroxicam Pure Drug

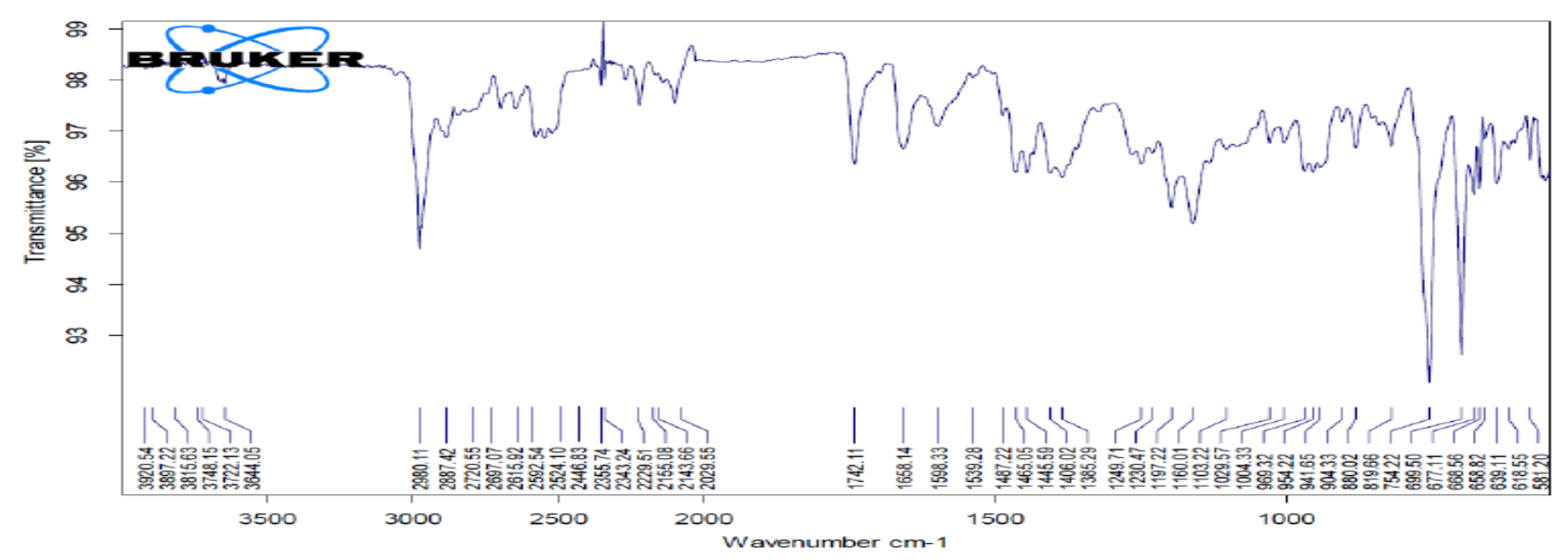

Figure 2: FT-IR spectra of Piroxicam optimized preparation

The studies of DSC thermal history of piroxicam shown that pointed endothermic peak at $203.7^{\circ} \mathrm{C}$, this indicates crystalline character of the piroxicam. Purified baobab fruit pulp pectin powder thermogram showed that baobab fruit pulp pectin powder is in amorphous nature. Endothermic peak of the piroxicam appear to be shifted to higher melting point $210^{\circ} \mathrm{C}$, in fact there is merging of piroxicam peak and mannitol peak as shown in the thermograms of formulations shown in Fig no 3. Thermal analysis studies acknowledged that there was no drug interaction with excipients utilized.

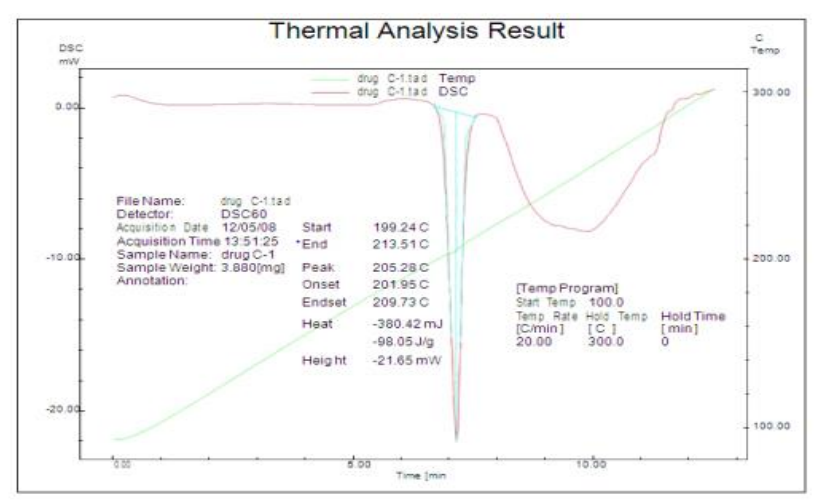

Figure 3: Thermal analysis: Results of DSC studies 
SEM photos of baobab fruit pulp pectin powder shown in Figure no 4.

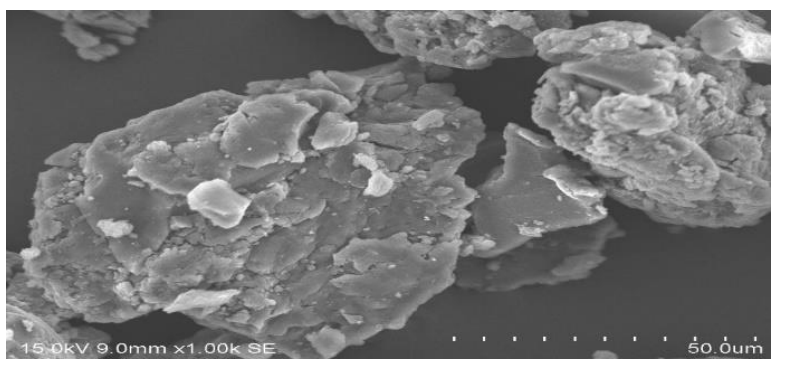

Figure 4: SEM studies of extracted Pectin powder of baobab fruit
The baobab fruit pulp pectin powder particles are unsymmetrical and surface was smooth and silky has noticed. The range of the particles sizes were approximately 50-200 $\mu \mathrm{m}$ in size was determined.

Granules, angle of repose were measured to be $27^{\circ}-35^{\circ}$ showing good quality of the flow rate of granules was noticed. The range of bulk density in between 0.28 to $0.42 \mathrm{gm} / \mathrm{cc}$ and tapped density to be in the range of 0.34 to $0.52 \mathrm{gm} / \mathrm{cc}$ were observed. Carr's index and Haunser ratios were founded to be in the range of 11.23 to 20.01 and 1.12 to 1.26 are shown in the table no.4. The above findings strongly indicating that results of granules compression outcome was very satisfactory.

Table 4: Pre-compression studies of prepared formulation granules of piroxicam

\begin{tabular}{|c|c|c|c|c|c|}
$\begin{array}{c}\text { Formulation- } \\
\text { Codes }\end{array}$ & Angle repose & $\begin{array}{c}\text { Bulk density } \\
\text { (g/ml) }\end{array}$ & $\begin{array}{c}\text { Tapped density } \\
\text { (g/ml) }\end{array}$ & $\begin{array}{c}\text { Percentage of } \\
\text { Carrs index }\end{array}$ & $\begin{array}{c}\text { Hausners } \\
\text { ratio }\end{array}$ \\
\hline F-1 & $35.13 \pm 1.032$ & $0.4236 \pm 1.0026$ & $0.4854 \pm 1.0018$ & $12.73 \pm 1.0494$ & $1.14 \pm 1.0014$ \\
\hline F-2 & $35.15 \pm 1.041$ & $0.4230 \pm 1.0020$ & $0.4766 \pm 1.0033$ & $11.23 \pm 1.1272$ & $1.12 \pm 1.0035$ \\
\hline F-3 & $29.24 \pm 1.008$ & $0.4127 \pm 1.0180$ & $0.4821 \pm 1.0029$ & $14.36 \pm 1.7566$ & $1.16 \pm 1.0000$ \\
\hline F-4 & $27.47 \pm 1.027$ & $0.4227 \pm 1.0038$ & $0.5231 \pm 1.0253$ & $19.19 \pm 1.0565$ & $1.23 \pm 1.0071$ \\
\hline F-5 & $35.12 \pm 1.019$ & $0.3823 \pm 1.0032$ & $0.4852 \pm 1.0044$ & $20.01 \pm 1.0848$ & $1.26 \pm 1.0000$ \\
\hline F-6 & $34.99 \pm 1.003$ & $0.3910 \pm 1.0014$ & $0.4650 \pm 1.0036$ & $15.90 \pm 1.3040$ & $1.16 \pm 1.0070$ \\
\hline F-7 & $33.86 \pm 1.002$ & $0.2896 \pm 1.0014$ & $0.3449 \pm 1.0013$ & $16.04 \pm 1.3676$ & $1.18 \pm 1.0424$ \\
\hline F-8 & $35.23 \pm 0.001$ & $0.3100 \pm 0.0035$ & $0.3655 \pm 0.0031$ & $15.19 \pm 0.2969$ & $1.17 \pm 0.0070$ \\
\hline F-9 & $32.61 \pm 0.001$ & $0.3925 \pm 0.0026$ & $0.4614 \pm 0.0028$ & $14.93 \pm 0.9545$ & $1.16 \pm 0.0070$ \\
\hline
\end{tabular}

Hardness about piroxicam prepared tablets had been founded in between $4.1 \mathrm{~kg} / \mathrm{cm}^{2}$ to $4.9 \mathrm{~kg} / \mathrm{cm}^{2}$. Friability percentage range was founded in between $0.24 \%$ to $0.75 \%$ and thickness was $3.15 \mathrm{~mm}$ to $3.75 \mathrm{~mm}$ apart from above results also observed percentage of drug content and in-vitro dissolution studies results are given in the table no.4. Hence, tablets prepared with baobab fruit pulp pectin powder as disintegrating agent provided required properties to tablets.

Table 5: Post compression parameters of piroxicam tablets

\begin{tabular}{|c|c|c|c|c|c|c|}
\hline $\begin{array}{c}\text { Formulation- } \\
\text { codes }\end{array}$ & $\begin{array}{c}\text { weight Average } \\
\text { in } \mathbf{~ m g}\end{array}$ & $\begin{array}{c}\text { Hardness in } \\
\mathbf{k g} / \mathbf{c m}^{2}\end{array}$ & $\begin{array}{c}\text { \%loss of } \\
\text { Friability }\end{array}$ & $\begin{array}{c}\text { Thickness in } \\
\mathbf{m m}\end{array}$ & $\begin{array}{c}\text { \% of Drug } \\
\text { content }\end{array}$ & $\begin{array}{c}\text { In vitro disintegration } \\
\text { Times in Sec }\end{array}$ \\
\hline F1 & 148.5 & 4.2 & 0.36 & 3.69 & 98.16 & 49 \\
\hline F2 & 149.3 & 4.9 & 0.24 & 3.48 & 97.62 & 36 \\
\hline F3 & 147.8 & 4.6 & 0.59 & 3.15 & 99.35 & 31 \\
\hline F4 & 145.6 & 4.1 & 0.37 & 3.75 & 96.28 & 15 \\
\hline F6 & 149.2 & 4.7 & 0.49 & 3.61 & 97.19 & 31 \\
\hline F7 & 148.8 & 4.3 & 0.36 & 3.95 & 99.25 & 28 \\
\hline F9 & 147.2 & 4.2 & 0.75 & 3.47 & 99.61 & 20 \\
\hline
\end{tabular}

Sizes of the Particles of all prepared formulations were observed to be in the range of $8 \mu \mathrm{m}$ to $18 \mu \mathrm{m}$ was confirmed by using microscopic technique. $\mathrm{pH}$ was found to be in the range of 5.29 to 6.82 .

In-vitro drug release investigations of piroxicam tablets revealed that in the case of $\mathrm{F} 1$ with in 45 minutes $93.12 \%$ of drug was released and where as in the case of F2 formulation $96.45 \%$ of drug within 30 minutes. Within 20 min $98.34 \%$ of drug was released in case of F3 and F4,
F5 formulations shown $89.67 \%$, 95.47\% of drug released within hour. As increased percentage levels of baobab fruit pulp pectin powder in the formulations showing enhancement in the means of time to releasing of drug about $98 \%$ as observed in the formulations. Formulation F3, is advanced from plan F1, F2, F4\& F5 as it delivered 98 $\%$ of the medication since F1, F2 and F3 didn't pass for the friability test and didn't possess enough hardness results are given in the table no. 6 and Fig no.5 . 
Table 6: Cumulative amount of drug released from piroxicam tablets prepared with different amounts of Baobab fruit pulp pectin powder

\begin{tabular}{|c|c|c|c|c|c|c|c|c|c|}
\hline & \multicolumn{8}{|c|}{ Cumulative Percent Drug Dissolved } \\
\hline & F-1 & F-2 & F-3 & F-4 & F-5 & F-6 & F-7 & F-8 & F-9 \\
\hline 0 & 0 & 0 & 0 & 0 & 0 & 0 & 0 & 0 & 0 \\
\hline 5 & 25.85 & 49.54 & 35.41 & 8.45 & 25.12 & 34.54 & 37.15 & 20.45 & 20.36 \\
\hline 10 & 43.61 & 58.43 & 68.51 & 15.46 & 39.46 & 43.12 & 48.34 & 45.46 & 45.42 \\
\hline 15 & 56.38 & 70.25 & 81.25 & 35.15 & 46.73 & 55.15 & 57.12 & 62.58 & 63.26 \\
\hline 20 & 75.14 & 83.54 & 98.34 & 46.78 & 55.14 & 61.24 & 73.42 & 70.51 & 79.13 \\
\hline 30 & 86.74 & 96.45 & - & 57.46 & 70.51 & 79.31 & 82.16 & 83.61 & 94.15 \\
\hline 45 & 93.12 & - & - & 70.23 & 83.61 & 91.87 & 90.02 & 96.45 & - \\
\hline 60 & - & - & - & 89.67 & 95.47 & - & 96.13 & - & - \\
\hline
\end{tabular}

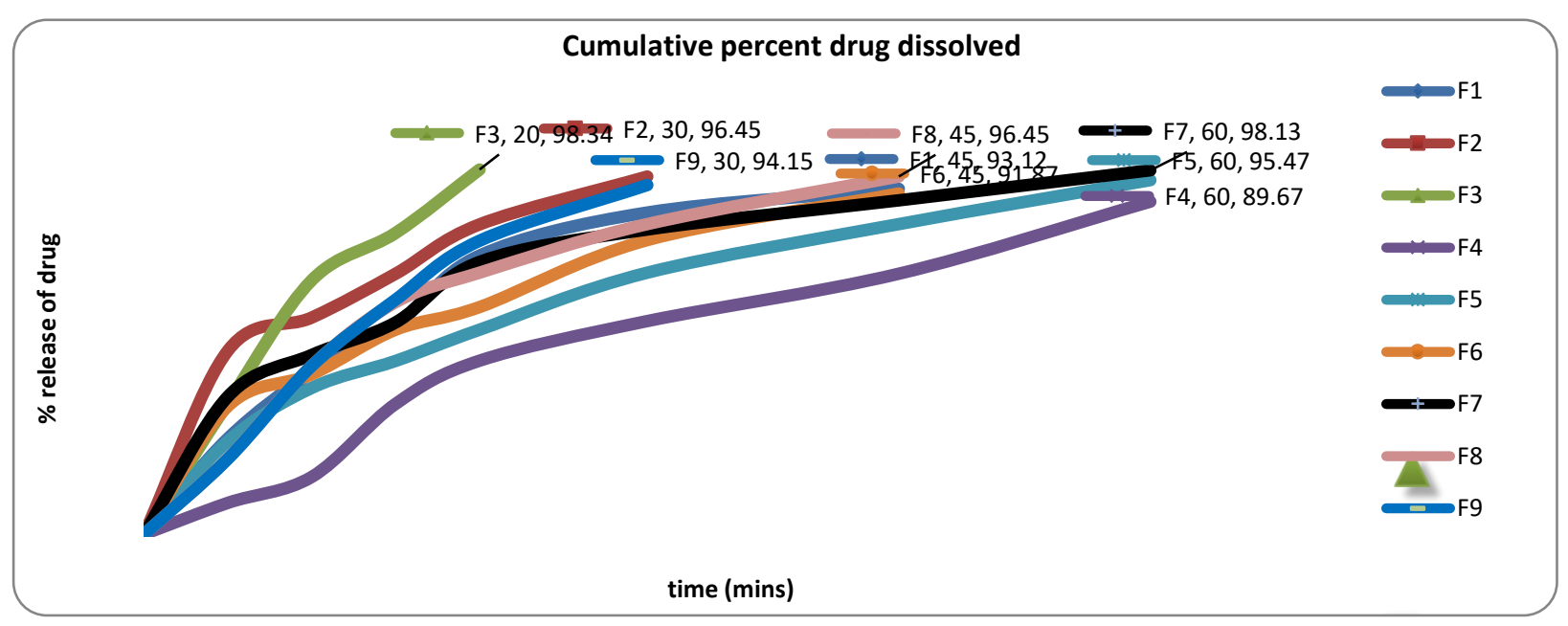

Figure 5: Cumulative Percent Drug Dissolved

The stability studies for optimized formulations were carried out at $40^{\circ} \mathrm{C} / 75 \% \mathrm{RH}$ for 90 days. Hence there were no-significant modifications in the drug content and also in the physical properties during the examination time frame.

\section{CONCLUSION}

The baobab fruit pulp pectin powder exhibited good disintegrating properties for the piroxicam tablets. The augmented concentration of pectin in the tablet formulations showing minute retardation in the drug release is evidence. Hence, this study strongly proving that powder of pectin extracted from baobab fruit pulp can be utilized as a pharmaceutical drug excipient.

\section{REFERENCES}

1. Femi-Oyewo MN, Adedokun MO, Olusoga TO. Evaluation of the suspending properties of Albiziazygia gum on sulphadimidine suspension. Trop J Pharm Res. 2004; 3(1): 279-284.

2. Khan L, Mahmood T. Drugs of natural origin. Tech Monitor. 2006; 53-56.
3. Mann AS, Jain NK, Kharya MD. Evaluation of the suspending properties of Cassia tora mucilage on sulphadimidine suspension. Asian J. Exp. Sci. 2007; 21(1): 63-67.

4. Kumar Ravi, Patil MB, Patil SR, Paschapur MS. Evaluation of Abelmoschus esculentus mucilage as suspending agent in paracetamol suspension. Int J Pharm tech Res. 2009; 1(3): 658-665.

5. Boyinbode MO, Iranloye TA. Preliminary investigations into some properties of Paracetamol granules prepared with naturally occurring gums. J.Pharm. 1986; 3: 37-41

6. Odeku OA, Akinlosotu OD. A preliminary evaluation of Khaya gum as an emulsifying agent. West Africa J. Pharm. 1997; 11(1): 30-33.

7. Odeku OA, Itiola OA, Ogbolu GO. Effect of formulation and processing variables on the emulsifying properties of two species of Khaya gum. West African J. Pharm. 1991; 13: 47-50.

8. The British Pharmaceutical Codex, Published by the Pharmaceutical Press, Cambridge, London, 12th Edition. 1994, pp158.

9. Patel NK, Kenon L, Levinson RS. Pharmaceutical Suspensions, In: The Theory and Practice of Industrial Pharmacy, 3rd Indian Edition, Vargheese Publishing House, Mumbai. 1986, pp 479-501.

\section{Source of Support: None declared.}

Conflict of Interest: None declared.

For any question relates to this article, please reach us at: editor@globalresearchonline.net New manuscripts for publication can be submitted at: submit@globalresearchonline.net and submit_ijpsrr@rediffmail.com 